\title{
The Reduction of Noxious Emissions Using Urea Based on Selective Non-Catalytic Reduction in Small Scale Bio Fuel Combustion System
}

\author{
Mohamad Shaiful Ashrul Ishak \\ School of Manufacturing Engineering, Universiti Malaysia Perlis \\ PO Box 77, Pejabat Pos Besar, 01000 Kangar, Perlis, Malaysia \\ Tel: 60-4-988-5018Ｆax: 60-4-988-5034Ｅ-mail: mshaiful@unimap.edu.my \\ Mohammad Nazri Mohd. Jaafar \\ Department of Aeronautics \& Automotive, Faculty of Mechanical Engineering \\ Universiti Teknologi Malaysia, 81310 UTM, Johor, Malaysia
}

Received: December 12, 2010

Accepted: January 5, 2011

doi:10.5539/mas.v5n2p108

The research is financed by Ministry of Science, Technology and Innovation Malaysia (MOSTI) under Science Fund Grant Scheme (06-01-15-SF0034).

\begin{abstract}
Selective Non-Catalytic Reduction (SNCR) of oxides of nitrogen (NOx) was studied experimentally by injecting different concentrations of aqueous urea solution in a pilot-scale Bio-fuel fired tunnel furnace at 3-4 \% excess oxygen level and with low ppm of baseline $\mathrm{NO}_{\mathrm{x}}$ ranging from 65 to $75 \mathrm{ppm}$ within the investigated temperature range. The furnace simulated small-scale combustion systems where the operating temperatures are usually in the range of about 973 to $1323 \mathrm{~K}$ and $\mathrm{NO}_{\mathrm{x}}$ emission level remains below $100 \mathrm{ppm} . \mathrm{NO}_{\mathrm{x}}$ reductions were studied with the variation of different parameters such as injection temperature, residence time, Normalized Stoichiometric Ratio (NSR) of the reagent, carrier gas pressure, etc. A significant amount of $\mathrm{NO}_{\mathrm{x}}$ reduction was achieved which was not pronounced by the previous researchers with urea SNCR for this low ppm of $\mathrm{NO}_{\mathrm{x}}$. With $5 \%$ plain urea solution, at an NSR of 4 as much as $54 \%$ reduction was achieved at $1128 \mathrm{~K}$, whilst in the additive case the $\mathrm{NO}_{\mathrm{x}}$ reduction was improved to as much as $69 \%$ at $1093 \mathrm{~K}$.
\end{abstract}

Keywords: Combustion, bio-fuel, NOx reduction, Selective Non-Catalytic Reduction (SNCR)

\section{Introduction}

Stringent regulations related to the abatement of $\mathrm{NO}_{\mathrm{x}}$ have led to the development of numerous $\mathrm{NO}_{\mathrm{x}}$ reduction techniques, which can be categorized in to three main strategies such as pre combustion fuel treatment, combustion modifications and post combustion exhaust gas treatment. Pre combustion fuel treatment concerns the reformulation of conventional fuels, treatment of fuels and choice of alternative fuels, which have low $\mathrm{NO}_{\mathrm{x}}$ emissions. Combustion modification regulates the production of $\mathrm{NO}_{x}$ by altering the combustion parameters such as flame peak temperature, equivalence ratio and mixing of air fuel. On the other hand, post combustion technologies are concerned with the treatment of flue gas before its exhaust out to the atmosphere without changing the combustion parameters. Any methods from a particular category can be combined with a method of different category and such case results in better $\mathrm{NO}_{\mathrm{x}}$ reduction performance than individual case (Rosenberg, $\mathrm{H}$. S., Curran, L. M., Slack, A. V., Ando, J. and Oxley, J. H, 1980).

Most of the combustion modifications are developed to control the formation of thermal $\mathrm{NO}_{\mathrm{x}}$ and however, demonstrated to be partially successful in reducing the fuel $\mathrm{NO}_{\mathrm{x}}$ (Bowman, C. T. 1992). Most of these approaches individually can achieve only moderate $\mathrm{NO}_{\mathrm{x}}$ control from the utility combustors (Irfan, N, 1996). They are applied to the furnaces and directly influence the combustion process and subsequently formation of $\mathrm{NO}_{\mathrm{x}}$. In some modifications such as water injection, reducing air preheats and firing rates some energy is lost which reduces the efficiency of the combustor (Schreiber, R. K., and Newman J. R. 1988). Aside from that such measures tend to produce undesirable levels of nitrous oxide and carbon monoxide and there is no known primary method that can reduce both $\mathrm{NO}_{\mathrm{x}}$ and carbon monoxide to an acceptable level without serious economic drawbacks. As a consequence of continuous extensive investigations some post combustion technologies are developed, which are related to the post combustion flue gas treatment and applied at the downstream of the $\mathrm{NO}_{\mathrm{x}}$ formation. Therefore, they are insensitive to the $\mathrm{NO}_{\mathrm{x}}$ formation mechanism (Lucas, D. and Brown, N. J. 1982). The post combustion $\mathrm{NO}_{\mathrm{x}}$ control involves either removal or destruction of nitrogen oxides present in the post combustion gases. Post combustion technologies can be applied successfully where the process modification approaches alone does not achieve the compliance with stringent emission standards (Bowman, C. T. 1992). 


\section{Selective Non-Catalytic Reduction}

SNCR involves the injection of a reducing reagent into the combustion effluent at relatively higher temperatures to react with $\mathrm{NO}_{\mathrm{x}}$. The reaction between $\mathrm{NO}_{\mathrm{x}}$ and $\mathrm{NO}_{\mathrm{x}}$ reducing agent occurs in a temperature window of 1144 to $1366 \mathrm{~K}$. Above this temperature window, the reagent might be oxidized resulting in the formation of additional $\mathrm{NO}_{\mathrm{x}}$ and below the window the rate of reaction becomes slow which may result in excessive ammonia slip (Rota, R., Antos, D., Zanoelo, E. F., Morbidelli, M, 2002). Some additives are applied to widen the reaction temperature range. If urea is used, the temperature window ranges from 1199 to $1310 \mathrm{~K}$. However, with the addition of additives, such as monomethylamine, dimethylamine, trymethylamine, cyanuric acid, carbamates, ammonium carbonate, ammonium bicarbonate or cyanurates, the effective temperature range expands to 1088 to 1421 K (Rota, R., Antos, D., Zanoelo, E. F., Morbidelli, M, 2002). In general, $\mathrm{NO}_{\mathrm{x}}$ reductions are lower and chemical consumption is higher as compared to SCR (Irfan, N. 1996). Typical reagent/inlet $\mathrm{NO}_{\mathrm{x}}$ stoichiometries are 2:1. Since SNCR does not require the use of a catalyst, capital costs are lower than with SCR. A number of reagents can be used as $\mathrm{NO}_{\mathrm{x}}$ reducing agents. But most common of them are ammonia and urea. The urea may be stored as a solid or mixed with water and stored as a solution.

Despite the fact that SCR has higher $\mathrm{NO}_{\mathrm{x}}$ reduction efficiency, it has several disadvantages which include high capital investment cost, higher operating cost than most other options, limited catalyst life, catalyst poisoning by the constituents present in the flue gas, catalyst erosion by dust, air heater plugging, erosion by ammonium bisulphate, large space requirement to install and higher upstream pressure to flow the flue gas through catalytic bed. Apart from that the continuous contact of the flue gases may disintegrate the catalyst and consequently it may behave as new pollution source. Usually stationary combustors have much longer lifetime so, any new emission technologies must be able to retrofit easily to the existing facilities. As the catalytic bed need large space so it is rather difficult to retrofit to the existing industrial boilers (Lyon, R. K. and Hardy, J. E. 1986)( Lyon, R. K. 1987).

In contrast, as SNCR has no use of catalyst, it has minimized all the problems of SCR. Moreover, it can be used in dirty and fouling services (Particulates and/or high sulfur) and it is easier to retrofit. For this, currently a number of SNCR installations have been adopted in coal, oil and gas fired power station boilers, industrial boilers, refineries and waste incinerators. As it requires little capital cost and easy to retrofit, it is best suited to developing countries. Recently, SNCR has been adopted in different industries in South Korea, China, Taiwan and the Czech Republic (Redojevic, M. 1998). Although it is inexpensive, capabilities of SNCR are limited by narrow temperature window of $\mathrm{NO}_{\mathrm{x}}$ control, ammonia slip and low utilization of $\mathrm{NO}_{\mathrm{x}}$ reducing agent. To mitigate these problems as well as to improve the $\mathrm{NO}_{\mathrm{x}}$ reduction efficiency lately, some additives are added with the urea or ammonia (Zamansky, V. M., Lissianski, V. V., Maly, P. M., Ho, L., Rusli, D. and Gardiner, W. C. Jr, 1999). They have shown that the $\mathrm{NO}_{\mathrm{x}}$ reduction efficiency can be improved as much as $90 \%$ by adding very small amounts of some additives with the urea solution.

The detailed reaction mechanism of NO reduction with the injection of urea is not clearly understood. Initially it was believed that thermo-cracking and decomposition lead to the production of $\mathrm{NH}_{\mathrm{i}}$ radicals that reduce NO to $\mathrm{N}_{2}$ and $\mathrm{H}_{2} \mathrm{O}$. Based on the chemical composition of urea it is assumed that per mole of urea generates two moles of $\mathrm{NH}_{2}$ radicals. Salimian and Hanson (Saliman, S. and Hanson, R. K. 1980) developed a kinetic model to predict the performance of urea. They assumed that $150 \mathrm{ppm}$ of urea might decompose rapidly to $150 \mathrm{ppm}$ of CO and $300 \mathrm{ppm}$ of $\mathrm{NH}_{2}$. The calculated result showed that the peak $\mathrm{NO}_{\mathrm{x}}$ reduction efficiency was comparable with ammonia injection but the reaction time was shorter. The prediction showed that the peak temperature of $\mathrm{NO}_{\mathrm{x}}$ reduction should be about $873 \mathrm{~K}$.

\section{Experimental Setup and Procedure}

A schematic diagram of the experimental set up is shown in Figure 1. The complete experimental set up mainly consists of burner, combustor, and injection system. A Riello brand 40G series-G10 light oil industrial burner was used for the experiment as a combustion source. All tests were conducted using Bio-fuel (B5\% - 5\% of palm oil and 95\% commercial diesel) as fuel. Fuel was injected at the back plate using central fuel injector with single fuel nozzle pointing axially outwards. A circular pilot-scale combustor or combustion chamber was used for the present experiment. The length and the outside diameter of the combustor were $1765 \mathrm{~mm}$ and $390 \mathrm{~mm}$ respectively. The material was $2.5 \mathrm{~mm}$ mild steel sheet. To reduce the heat transfer in order to get high temperature inside the combustor as well as to protect the combustion chamber wall being overheated, a $50 \mathrm{~mm}$ refractory lining of KIMCAST LW 11 material was used. Injector for reagent injection was placed at the downstream of the flame zone, i.e. at post combustion zone as SNCR is concerned with the post combustion flue gas treatment. Usually, in the injection zone the $\mathrm{NO}_{\mathrm{x}}$ reducing reagent is injected into the combustion effluent from a single or multiple injectors. In this zone also most of the reagent is mixed with the flue gas. A $70^{\circ}$ cone spray dual fluid injector was used in the present studies. The injection zone started from $700 \mathrm{~mm}$ downstream of the burner end and continued up to about $1100 \mathrm{~mm}$. At the injector section one temperature tapping was made in order to provide the facility to measure the temperature of injection.

After finishing the fabrication of the combustion chamber, some baseline tests were performed. These tests were 
performed without injecting the urea. During the tests the temperatures at different points of the combustion chamber were measured using a 12 channel digital thermocouple recorder inserting the thermocouple probes into the combustion chamber through different temperature tappings. The probes were protruded up to the center point of the combustion chamber along the mean line as the tappings were fabricated along the mean line. At the same time the $\mathrm{NO}_{\mathrm{x}}$ and other components of the exhaust gas were measured at the exhaust section by a continuous flue gas monitor at different flue gas temperatures, which range from 973 to $1400 \mathrm{~K}$. During the tests the excess oxygen level in the combustion effluent was kept in the range of $3-4 \%$ adjusting the airflow rate of the burner.

\section{Results and Discussions}

Experiments were performed using $5 \%$ aqueous urea solution to investigate the $\mathrm{NO}_{\mathrm{x}}$ reduction, effective temperature window and peak temperature of $\mathrm{NO}_{\mathrm{x}}$ reduction with the variation of injection temperature, residence time and normalized stoichiometric ratio. The tests were performed in a range of Normalized Stoichiometric Ratio (NSR) from 1 to 4, temperatures from 973 to $1323 \mathrm{~K}$ and residence time for $815 \mathrm{~mm}$ of reactor.

\subsection{Effect of Normalized Stoichiometric Ratio}

Figures 2 show the effect of normalized stoichiometric ratio on the $\mathrm{NO}_{\mathrm{x}}$ reduction. Reduction increased with the increase in NSR. For optimum temperature i.e. at $1128 \mathrm{~K}$, the $\mathrm{NO}_{\mathrm{x}}$ reduction rose moderately with the increase in NSR, whilst at a temperature of $1273 \mathrm{~K}$, which is higher than the optimum value, the rising was not smooth. Between the NSR 2 and 3 the improvement was quite dramatic and it was about $26 \%$, whereas at $1128 \mathrm{~K}$, between those two points the improvement was only about $7 \%$. Figure 2 also show that the width of the effective temperature window widened with the increasing value of NSR, but the peak temperature of $\mathrm{NO}_{\mathrm{x}}$ reduction was almost unaffected with such variation and remained centered at approximately $1128 \mathrm{~K}$. Between NSR of 2 and 3 , for a reduction efficiency of $41 \%$ the effective temperature range was increased by $155 \mathrm{~K}$. This phenomenon of widening of temperature window with increase in molar ratio is in agreement with the findings of Wenli et al. (Wenli, D., Dam-Johansen, K. and Ostrergaard, K. 1989) and Irfan (Irfan, N. 1996).

The improvement of $\mathrm{NO}_{\mathrm{x}}$ reduction with the increases in NSR is supported by so many researchers such as Nylander et al. (Nylander, J. H., Mansour, M.N. and Douglas, R.B, 1989), Jones et al. (Jones, D. G., Muzio, L. J., Stocker, E., Nuesch, P.C., Nagrea, S., Ofenbau, K.K, Lautenschlager, G., Wachter, E. and Rose, G. 1989) and Irfan (Irfan, N. 1996). The flow momentum as well as spray angle increases with the increases in the reagent flow. Reagent with high momentum can easily penetrate the high velocity flue gas flow and thus enhances good reagent-flue gas mixing. Wider spray angle covers a large area in the combustor and thus contributes to rapid and effective reagent-flue gas mixing. So, when NSR increases, the amount of reagent increases, which attains better penetration and more effective mixing of reagent and flue gas inside the reactor and ultimately results in better $\mathrm{NO}_{\mathrm{x}}$ reduction than before. At a particular pressure and flow rate of the atomizing air, increasing amount of reagent makes the droplets coarser, which survive long time in the high temperature effluent and thus improve the reaction performance.

\subsection{Effect of Residence Time}

Figures 3 and 4 present the $\mathrm{NO}_{\mathrm{x}}$ reduction and initial concentration of $\mathrm{NO}_{\mathrm{x}}$ as a function of residence time respectively. In Figures 3 and $4, \mathrm{NO}_{\mathrm{x}}$ reduction increased with increases in residence time. Between the residence time 262 and $355 \mathrm{~ms}$, in case of $1173 \mathrm{~K}$ the reduction was faster. This rise is due to the fact that within that small part of the reactor the average reaction temperature was very close to the peak reaction temperature of $1128 \mathrm{~K}$. On the contrary, at $1093 \mathrm{~K}$ case, the rate of $\mathrm{NO}_{\mathrm{x}}$ reduction is faster up to a residence time of $262 \mathrm{~ms}$ i.e. at the first part of the reactor, as in this case within this part of the reactor temperatures are close to the optimum temperature.

For both cases after a certain value of residence time, with the increase in residence time the rate of $\mathrm{NO}_{\mathrm{x}}$ reduction decreased and the profiles gradually straightened up. This is due to fact that in the present study the reactor temperature was not maintained constant along the length of the reactor. So, with the increase in the residence time the reaction temperature reduced, which caused gradual reduction in reaction rate within the investigated range of the residence time.

Apart from the low temperature effect, this rate might decrease due to low reagent flue gas ratio. As the residence time increases the amount of active reagent to flue gas ratio decreases along the downstream of the reactor, which may cause poor reaction performance. This trend of reaction profile suggests that based on the operating conditions, after a certain length, the combustion chamber has no significant effect on reaction performance and this phenomenon is in accordance with the findings of the prior studies reported by (Irfan, N. 1996).

\section{Conclusions}

The followings are the main conclusions deduced from the investigations. The effective temperature window in the present studies is in the range of about $973 \mathrm{~K}$ to about $1300 \mathrm{~K}$, which suggests that the Selective 
Non-Catalytic Reduction of $\mathrm{NO}_{\mathrm{x}}$ using commercial grade urea in the Bio-fuel (B5\%) burning exhaust could be used effectively for low temperature application without using any additives. Secondly, the Selective Non-Catalytic Reduction of $\mathrm{NO}_{\mathrm{x}}$ using commercial grade urea demonstrates substantial $\mathrm{NO}_{\mathrm{x}}$ reduction in the Bio-fuel (B5\%) burning exhaust containing low ppm of initial $\mathrm{NO}_{\mathrm{x}}$. At an $\mathrm{NSR}$ of 4 , a maximum of $54 \% \mathrm{NO}_{\mathrm{x}}$ reduction is achieved and this much of $\mathrm{NO}_{\mathrm{x}}$ reduction was not pronounced by the previous researchers in their SNCR studies with low ppm of baseline $\mathrm{NO}_{\mathrm{x}}$.

\section{References}

Bowman, C. T. (1992). Control of Combustion-Generated Nitrogen Oxide Emissions: Technology Driven by Regulation. Proceedings of the Twenty-Fourth Symposium (International) on Combustion. Combustion Institute, Pittsburgh. 859-878.

Irfan, N. (1996). Selective Non-catalytic reduction of $N O_{x}$. Unversity of Leeds: Ph.D Thesis.

Jones, D. G., Muzio, L. J., Stocker, E., Nuesch, P.C., Nagrea, S., Ofenbau, K.K, Lautenschlager, G., Wachter, E. and Rose, G. (1989). Two stage DeNO $_{x}$ Process Test Data for 300 TPD MSW Incineration Plant. The Proceedings of the 82nd APCA Meeting and Exhibition. Anaheim, CA. No. 8. 21-27.

Lucas, D. and Brown, N. J. (1982) Characterization of the Selective Reduction of NO by $\mathrm{NH}_{3}$, Combustion and Flame. (47): 219-234.

Lyon, R. K. and Hardy, J. E. (1986). Discovery and Development of the Thermal DeNO ${ }_{\mathrm{x}}$ Process, Industrial and Engineering Chemistry Fundamentals. 25. 19-24.

Lyon, R. K. (1987). Thermal DeNOx; Controlling $\mathrm{NO}_{\mathrm{x}}$ Emission by Non-Catalytic Process. Environmental Science and Technology. (21): 231-236.

Nylander, J. H., Mansour, M.N. and Douglas, R.B. (1989). Demonstration of an Automated Urea Injection System at Encina Unit 2. The Proceedings of the Joint EPA/EPRI Symposium on Stationary Combustion NO Control. San Francisco. No. 9, 35-56.

Redojevic, M. (1998). Reduction of Nitrogen Oxides in Flue Gases. Environmental Pollution. 102. 685-689.

Rosenberg, H. S., Curran, L. M., Slack, A. V., Ando, J. and Oxley, J. H. (1980). Post Combustion Methods for Control of $\mathrm{NO}_{\mathrm{x}}$ Emissions. Progress in Energy and Combustion Science. 6. 287-302.

Rota, R., Antos, D., Zanoelo, E. F., Morbidelli, M. (2002). Experimental and Modeling Analysis of the $\mathrm{NO}_{\mathrm{x}} \mathrm{OUT}$ Process. Chemical Engineering Science. (57): 27-38.

Saliman, S. and Hanson, R. K. (1980). Kinetic Study of NO Removal from Combustion Gases by $\mathrm{NH}_{\mathrm{i}}-$ Containing Compound. Combustion Science and Technology. (23): 225-230.

Schreiber, R. K., and Newman J. R. (1988). Acid Precipitation Effects on Forest Habitats: Implications for Wildlife. Conservation Biology 2:249-259.

Wenli, D., Dam-Johansen, K. and Ostrergaard, K. (1989). The Influence of Additives on Selective Non-Catalytic Reduction of Nitric Oxide with Ammonia. ACHEMASIA. Beijing.

Zamansky, V. M., Lissianski, V. V., Maly, P. M., Ho, L., Rusli, D. and Gardiner, W. C. Jr. (1999). Reactions of Sodium Species in the Promoted SNCR Process. Combustion and Flame. (117): 821-831.

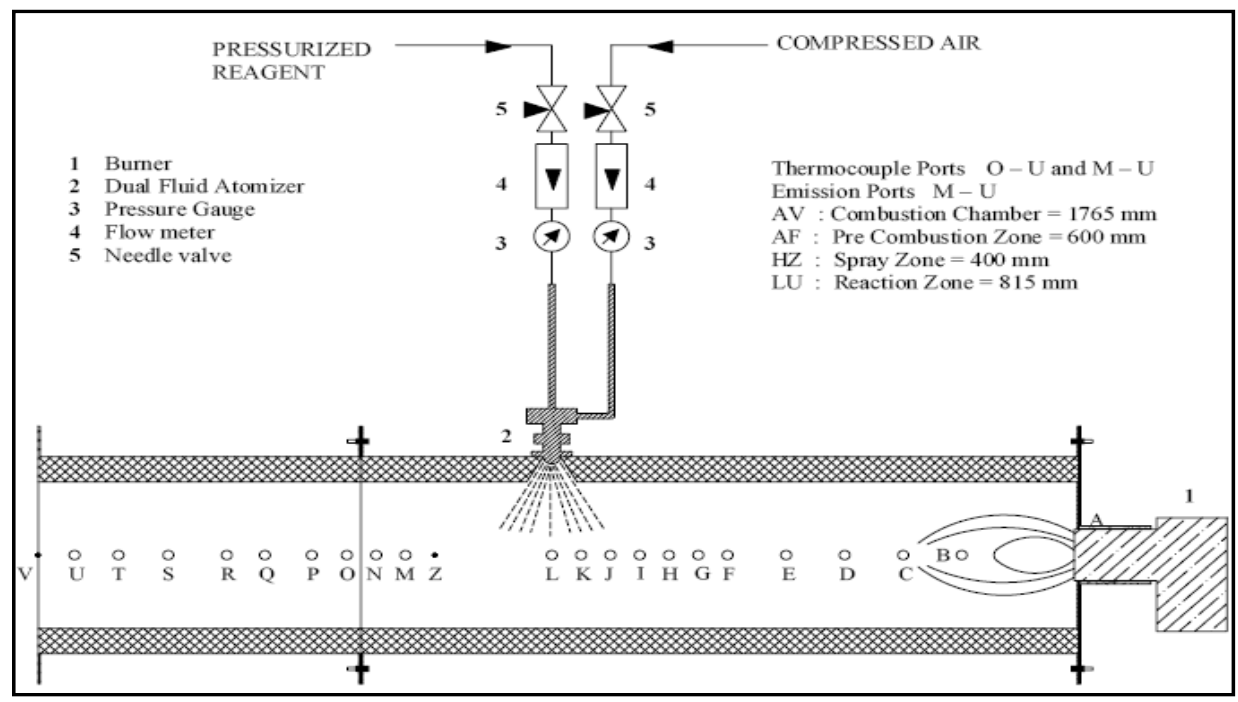

Figure 1. Layout of the Experimental Set Up 


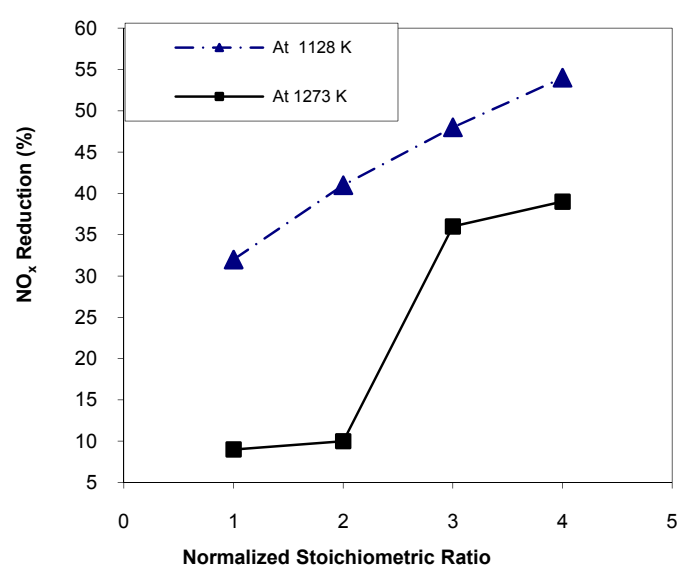

Figure 2. Effect of $\mathrm{NSR}$ on $\mathrm{NO}_{\mathrm{x}}$ reduction for $5 \%$ urea solution

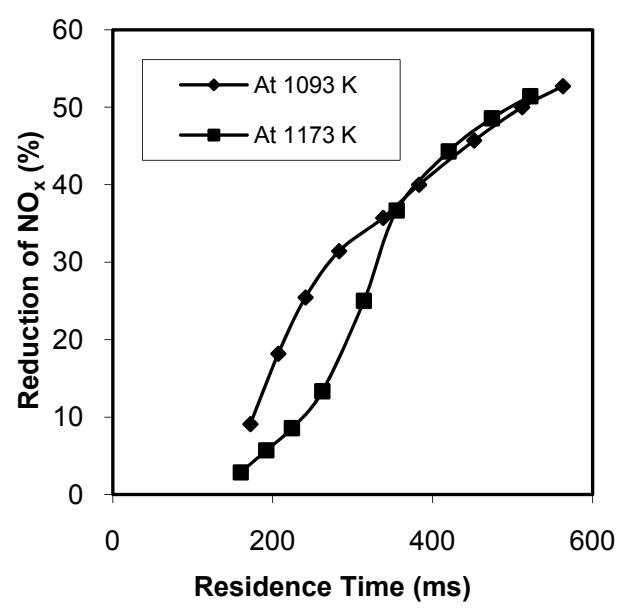

Figure 3. Effect of residence time on $\mathrm{NO}_{\mathrm{x}}$ reduction at NSR of 4

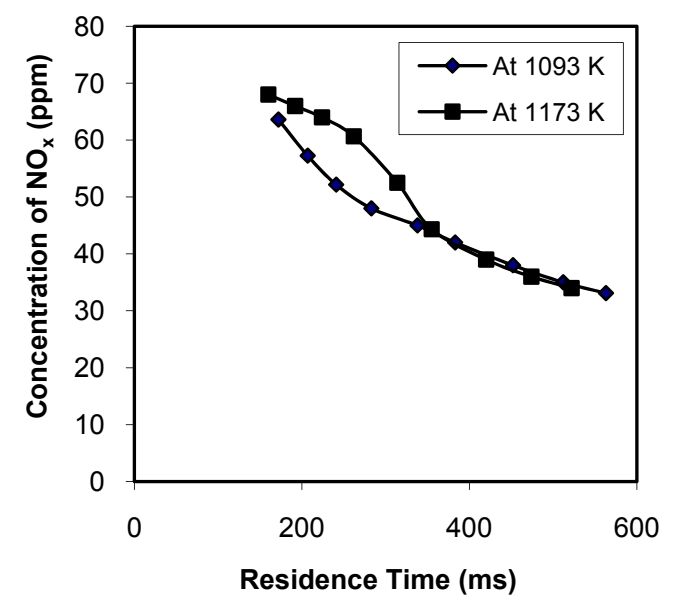

Figure 4. Effect of residence time on $\mathrm{NO}_{\mathrm{x}}$ reduction at NSR of 4 